\title{
MODELING SHEET FLOW UNDER BREAKING WAVES ON A SURF ZONE SANDBAR
}

\author{
Yeulwoo Kim, University of Delaware, ykim@udel.edu \\ Ryan S. Mieras, University of Delaware, rmieras@udel.edu \\ Zhen Cheng, Woods Hole Oceanographic Institution, zcheng@whoi.edu \\ Tian-Jian Hsu, University of Delaware, thsu@udel.edu \\ Jack A. Puleo, University of Delaware, ipuleo@udel.edu
}

\begin{abstract}
INTRODUCTION
Wave-driven sediment transport is one of the main drivers of beach morphodynamics. However, the creation of a comprehensive numerical model remains to be a challenging task due to complex mechanisms associated with unsteadiness and free-surface effects. Particularly for highly non-linear and skewed-asymmetric breaking waves, the boundary layer approximation (i.e., assuming horizontal pressure gradient is equal to local free-stream acceleration) is questionable. Moreover, wave-breaking-induced turbulence may approach the bed and further enhance sediment transport. Thus, a numerical model that can resolve the entire water column from the bottom boundary layer to the free-surface can be a powerful tool to understand wavedriven sediment transport.
\end{abstract}

\section{MODELING APPROACH}

An Eulerian two-phase flow model, SedFoam (Cheng et al., 2017) is combined with a volume-of-fluid solver, interFoam/waves2Foam (Berberović et al., 2009; Jacobsen et al., 2011) in the OpenFOAM framework. The fully coupled model, named SedWaveFoam, treats the air and water phases as two immiscible fluids with the interface evolution resolved, and the sediment particles as dispersed phase. The full profiles of flow and sediment transport driven by surface waves are calculated using Reynolds-averaged Eulerian two-phase flow equations with closures of inter-granular stresses and a $k-\varepsilon$ turbulence model. Because the surface waves and sheet flow processes are fully resolved, the effect of waveinduced bottom shear stress, pressure gradients, boundary layer streaming, and wave-breaking-induced turbulence in the bottom boundary layer can be investigated. SedWaveFoam was recently validated with the large wave flume experiment of Dohmen-Janssen and Hanes (2002) for sheet flow under non-breaking monochromic waves (Kim et al., 2017).

\section{PRELIMINARY RESULTS}

In this study, SedWaveFoam was applied to model the sandBAR SEDiment transport experiment (BARSED; Mieras et al., 2017). The numerical model was first tested using a coarse numerical resolution $(\Delta x=10 \mathrm{~mm}, \Delta z>2$ $\mathrm{mm}$ ), and waves with a period of $7.0 \mathrm{~s}$ and wave height of $0.66 \mathrm{~m}$ at the toe of the profile. The numerical model domain is a 2D flume that has exactly the same length and depth as in the physical experiment (Figure 1a). The break-point is located right on the sandbar crest in the model (Figure 1a) in agreement with observations (Mieras et al., 2017). The temporal evolutions of free-surface and streamwise velocity are shown in Figure $1 \mathrm{~b}$ and $1 \mathrm{c}$. Overall, the model is able to predict the free-surface elevation and streamwise velocity well. Based on the wave shape, an asymmetric wave velocity is observed to drive bottom sediment transport. Figure 1d shows a snapshot of volumetric sediment concentration near the bed, demonstrating the capability of the model to simulate sheet flow and bed evolution under the action of breaking waves. Because undertow has not yet developed in the first several waves, net onshore transport was observed.
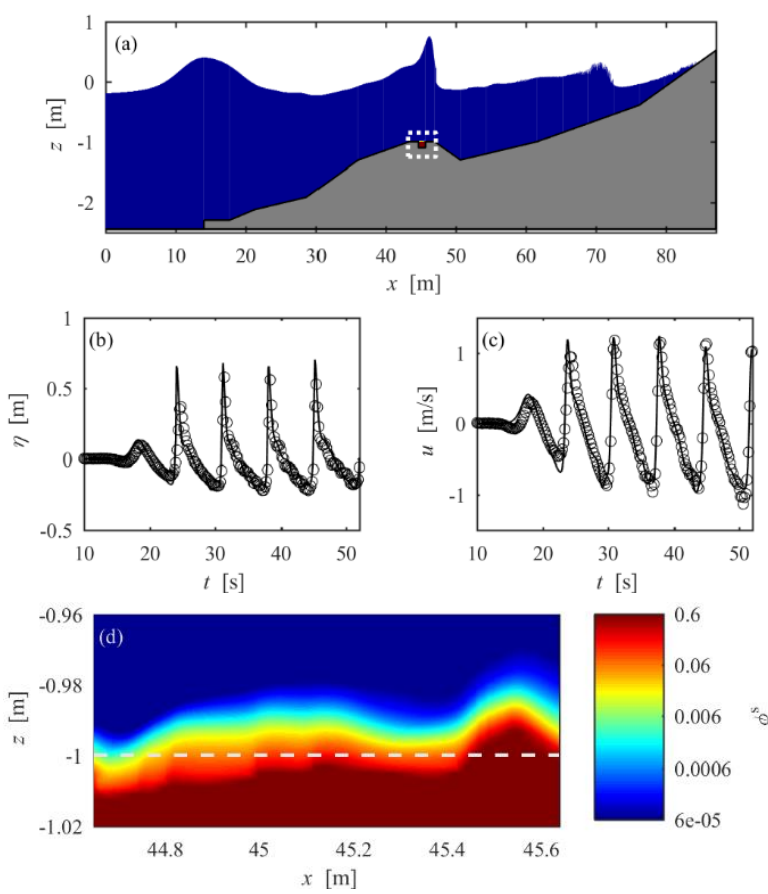

Figure 1 Snapshots of (a) the entire numerical flume at $t$ $=45 \mathrm{~s}$ (air, water and sediment phases are represented by white, blue and red, respectively). Measured (circles) and modeled (lines) time series of (b) free-surface elevation at $x$ $=46.876 \mathrm{~m}$ and (c) streamwise velocity at $x=45.143 \mathrm{~m}$ and $z=-0.486 \mathrm{~m}$. (d) Enlarged view of the sediment pit on the sandbar crest (white dashed box in Figure 1a) with the initial bed level plotted as a dashed white line.

\section{REFERENCES}

Berberović, van Hinsberg, Jakirlić, Roisman, Tropea (2009): Drop impact onto a liquid layer of finite thickness: Dynamics of the cavity evolution, Phys. Rev., E79, 036306.

Cheng, Hsu, Calantoni (2017): SedFoam: A multidimensional Eulerian two-phase model for sediment transport and its application to momentary bed failure, Coastal Eng., 119, 32-50.

Jacobsen, Fuhrman, Fredsøe (2011): A wave generation toolbox for the open-source CFD library: OpenFoam[ , Int. J. Numer. Methods Fluids, 70(9), 1073-1088.

Kim, Cheng, Hsu, Mieras, Puleo (2017): A numerical investigation of sheet flow under non-breaking and breaking waves, Coast. Dyn. 2017, Helsingør, Denmark. Mieras, Puleo, Anderson, Cox, Hsu (2017): Large-scale experimental observations of sheet flow on a sandbar under skewed-asymmetric waves, J. Geophys. Res. Oceans, 122, 5022-5045. 